\title{
INTEGRASI TEKNOLOGI PENGIDERAAN JAUH DAN SISTEM INFORMASI GEOGRAFIS UNTUK ESTIMASI SERAPAN DAN EMISI CO2 DI KOTA DENPASAR
}

\author{
I Wayan Nuarsa ${ }^{1,2 *}$, Abd. Rahman As-syakur ${ }^{2,3)}$, I Gusti Alit Gunadi ${ }^{1,2)}$ \\ dan I Made Sukewijaya ${ }^{1)}$ \\ ${ }^{1)}$ Program Studi Agroekoteknologi Fakultas Pertanian Universitas Udayana \\ ${ }^{2)}$ Pusat Penelitian Lingkungan Hidup Universitas Udayana \\ ${ }^{3)}$ Center for Remote Sensing and Ocean Science (CReSOS) Universitas Udayana \\ *Email: nuarsa@unud.ac.id
}

\begin{abstract}
Rapid economic growth in the Denpasar City has an impact on the rate of population growth. This will lead to increasing land requirements for settlements, infrastructure, and other supporting facilities. Meanwhile, the availability of land for green open space (RTH) will decrease. Several studies show that from year to year the area of vegetation cover decreases, and the air temperature in Denpasar City is increasing. Therefore, research to calculate $\mathrm{CO}_{2}$ uptake by urban plants and $\mathrm{CO}_{2}$ emissions from various activities in the city of Denpasar is needed to be done. Estimates of $\mathrm{CO}_{2}$ uptake by plants are carried out using remote sensing technology and GIS. Meanwhile, the calculation of $\mathrm{CO}_{2}$ emissions is carried out by an inventory of $\mathrm{CO}_{2}$ pollutant sources from point sources, areas sources, and mobile sources. The output of this study is a distribution map of $\mathrm{CO}_{2}$ absorption and emissions. From the map it can be seen whether the $\mathrm{CO}_{2}$ emissions of Denpasar City are higher than the ability of existing plants to absorb them.

The results showed that the ability of plants in Denpasar as a green open space to absorb $\mathrm{CO}_{2}$ was $235,780.63 \mathrm{tCO}_{2} /$ year, while total emissions from pollutant sources were $862,955,856 \mathrm{tCO}_{2} /$ year. The sources of $\mathrm{CO}_{2}$ emissions include from point source 37,649 tons/year, from source area 95,310 tons/year, and from mobile sources at $862,955,856$ tons/year. From the movable source the biggest contributor to $\mathrm{CO}_{2}$ emissions is light vehicles, which amounted to 540,355.88 tons/year (62.63\%), then followed by motorcycles at 260,187.43 tons/year (30.16\%). The amount of $\mathrm{CO}_{2}$ emissions in Denpasar City is 3.66 times greater than the ability of plants to absorb $\mathrm{CO}_{2}$ in 2015 and there is a tendency for this gap to be even greater in the future.

To overcome this problem, regulations are needed such as reducing the number of motorized vehicles by increasing public transportation services. The use of vehicles using energy sources other than fuel such as electricity is another alternative to consider. Finally, the increase in the number and quality of green open spaces is a conventional method that needs to be done.
\end{abstract}

Keywords: remote sensing,GIS,Landsat, $\mathrm{CO}_{2}$ uptake, $\mathrm{CO}_{2}$ emissions. 


\section{PENDAHULUAN}

Perkembangan pembangunan di berbagai sektor di daerah perkotaan berdampak terhadap pertambahan jumlah penduduk, peningkatan jumlah kendaraan bermotor, dan peningkatan kegiatan perekonomian. Hal ini akan berimplikasi terhadap peningkatan kebutuhan lahan (Tinambunan, 2006) dan berimplikasi pada penurunan tutupan vegetasi dan ruang terbuka hijau (RTH).RTH merupakan persentase tutupan vegetasi di daaerah perkotaan yang mempunyaiperanan sangat penting dalam penataan, karena RTH mempunyai fungsi ekologis, estetika, sosial budaya, dan ekonomi (Purnomohadi, 2006). Dilain pihak, vegetasi adalah penyerap utama $\mathrm{CO}_{2}$ di udara melalui proses fotosintesis dan berfungsi sebagai carbon sink di wilayah daratan(Nowaket. al., 1998).

Di sisi lain, aktivitas penduduk perkotaan dibidang industri, pariwisata dan rumah tangga yang menggunakan bahan bakar minyak bumi menyebabkan timbulnya emisi gas-gas rumah kaca seperti $\mathrm{CO}_{2}$ dan $\mathrm{CFC}$. Gas $\mathrm{CO}_{2}$ adalah salah satu yang paling penting peranannya dalam proses pemanasan global dan perubahan iklim. Beberapa sumber utama $\mathrm{CO}_{2}$ dari aktivitas penduduk di perkotaan antara lain adalah transportasi, pembangkit listrik, industri, perkantoran, hotel dan restoran. Hasil penelitian di Palembang menunjukan bahwa pada tahun 2010 jumlah emisi $\mathrm{CO}_{2}$ dari seluruh aktivitas penduduk mencapai 2,95 juta ton dengan aktivitas penyumbang $\mathrm{CO}_{2}$ tersebesar adalah industri skala besar dan transportasi (KLH, 2013).

Laju pertumbuhan penduduk yang tinggi di Kota Denpasar dengan berbagai konsekunsinya merupakan penyebab utama terdesaknya alokasi ruang untuk vegetasi yang mempunyai fungsi sangat penting di daerah perkotaan, sementara akan terjadipeningkatan pencemaran dan suhu udara. Denpasar merupakan kota dengan pertumbuhan penduduk yang pesat. Jumlah penduduk Kota Denpasar tahun 2000 adalah 398.932 jiwa, sedangkan pada Tahun 2014 meningkat menjadi 863.600 jiwa sehingga rata-rata pertumbuhan penduduk Kota Denpasar dari tahun 2000 sampai 2014 adalah $8,32 \%$ per tahun. Kota Denpasar merupakan salah satu kota dengan tingkat pertumbuhan tertinggi di Indonesia,juga dengan tingkat kepadatan yang cukup tinggi yaitu 6.759 jiwa per $\mathrm{km}^{2}$ (BPS Kota Denpasar, 2015). Sementara itu, luasan tutupan vegetasi semakin berkurang. Hasil penelitian Diarniti (2006) dengan menggunakan citra Landsat menunjukkan bahwa luasan tutupan vegetasi Kota Denpasar menurun dari 5707.05 ha di tahun 1994 menjadi 2249.97 ha pada tahun 2003.Perubahan luasan tutupan vegetasi dan peningkatan kadar gas $\mathrm{CO}_{2}$ atmosfer di perkotaan merupakan masalah yang serius. $\mathrm{CO}_{2}$ bersama gas-gas rumah kaca yang lain berperan dalam meningkatkan suhu global dan khususnya terhadap efek pulau panas (heat island) perkotaan. Hasil penelitian Nuarsa dkk (2012) dan As-syakur et al (2012) tentang fenomenaurban heat island di Kota Denpasar menggunakan data penginderaan jauh dan GIS menunjukkan bahwa terjadi peningkatan suhu udara rata-rata di Kota Denpasar dari $27,28^{\circ} \mathrm{C}$ di tahun 1995 menjadi $29,44^{\circ} \mathrm{C}$ di tahun 2003. Vegetasi memerlukan $\mathrm{CO}_{2}$ dalam proses fotosisntesis. Penyerapan $\mathrm{CO}_{2}$ oleh vegetasi di perkotaan merupakan proses pengendalian pencemaran udara. Oleh sebab itu, perlu dilakukan kajian dan perbandingan tentang jumlah $\mathrm{CO}_{2}$ yang dapat diserap oleh vegetasi dan jumlah emisi $\mathrm{CO}_{2}$ dari berbagai aktivitas di Kota Denpasar. 
Penelitian pengunaan teknologi penginderaan jauh untuk monitoring vegetasi telah banyak dilakukan (Nuarsa, 2013, Nuarsa et al, 2012, As-Syakur et al, 2012, Nuarsa et al, 2011, Nuarsa et al, 2010, Nuarsa et al, 2007, Nuarsa et al, 2005).Teknologi penginderaan jauh dengan pendekatan berbasis spasial dapat merekam dan menganalisis secara spasial perubahan yang terjadi.Sensor penginderaan jauh mempunyai kemampuan dalam menangkap gelombang yang dipantulkan oleh vegetasi dan non vegetasi serta mampu membedakan jumlah klorofil dan Leaf Area Index (LAI) vegetasi melalui pemanfaatan nilai indeks vegetasi. Nilai indeks vegetasi merupakan suatu nilai yang dihasilkan dari persamaan matematika dari beberapa band citra penginderaan jauh yang menghasilkan satu nilai indeks (As-syakur dan Adnyana, 2009). Indeks vegetasi dirancang untuk memperjelas tampilan objek berklorofil (vegetasi) dibandingkan dengan objek-objek yang tidak berklorofil. Nilai indeks vegetasi dapat memberikan informasi tentang persentase penutupan vegetasi, indeks tanaman hidup (Leaf Area Index), biomassa tanaman, fAPAR (fraction of Absorbed Photosynthetically Active Radiation), kapasitas fotosintesis dan estimasi penyerapan karbon dioksida $\left(\mathrm{CO}_{2}\right)$ (Horning, 2004; Ji and Peters, 2007). Penelitian ini bertujuan untuk membandingkan kemampuan tanaman menyerap $\mathrm{CO}_{2}$ melalui proses fotosintesis dan jumlah emisi $\mathrm{CO}_{2}$ total yang dihasilkan oleh seluruh kegiatan di Kota Denpasar pada tahun 2015.

\section{METODOLOGI}

\subsection{Lokasi Penelitian}

Penelitian ini dilakukan di Kota Denpasar yang terletak diantara 08³5’31"- 0844'49” Lintang Selatan dan $115^{\circ} 10^{\prime} 23^{\prime \prime}-115^{\circ} 16^{\prime} 27^{\prime \prime}$ Bujur Timur (Gambar 1), dengan luas wilayah $125,95 \mathrm{~km}^{2}$ atau $12.595 \mathrm{ha}$.

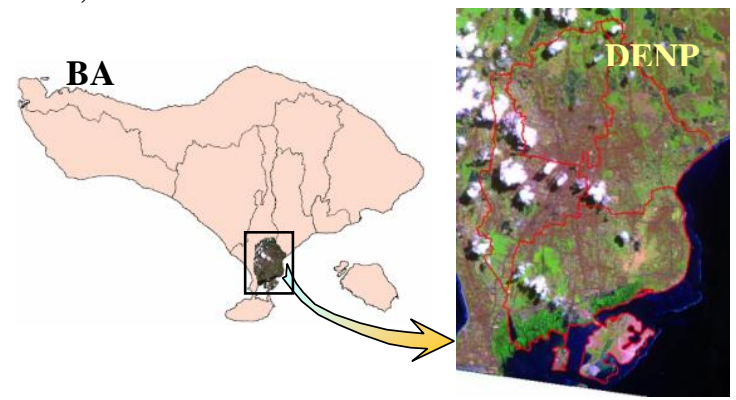

Gambar 1.

Lokasi penelitian

\subsection{Bahan dan Perangkat Lunak}

Bahan-bahan yang digunakan dalam penelitian ini adalah:

1. Citra Landsat 8 Level $1 \mathrm{~T}$ - Terrain Corrected tahun 2015

2. Data suhu Kota Denpasar dari BMKG stasiun Sanglah-Denpasar

3. Data spasial Kota Denpasar berformat SIG

Perangkat lunak untuk analisis digital adalah ENVI 4.4 dan ArcView 3.3 dengan bantuan extensions Spatial Analyst, sedangkan untuk analisis statistik digunakan perangkat lunak Microsoft Excel 2013. Struktur data SIG yang digunakan adalah struktur data raster dengan ukuranpixel30meter dan struktur data vektor.

\subsection{Prosedur Penelitian \\ 2.3.1. Perhitungan Serapan $\mathrm{CO}_{2}$}

Sebelum proses pengolahan citra untuk mencari nilai indeks vegetasi dan mengestimasi jumlah penyerapan $\mathrm{CO}_{2}$ di Denpasar, maka ada langkah-langkah yang harus dilakukan untuk memperbaiki atau mengkoreksi citra sehingga citra tersebut dapat dibaca atau terlihat sesuai dengan keadaan dan posisi sebenarnya di permukaan bumi. Adapun proses-proses terbut adalah:

A. Konversi nilai digital ke nilai reflektan 
Koreksi ini bertujuan mengubah nilai digital Landsat 8 menjadi nilai reflektannya dengan melakukan kalibrasi terhadap nilai standar dan

memperhitungkan sudut elevasi matahari.Rumus yang digunakan didasarkan atas USGS (2014), sebagai berikut:

$\rho \lambda=\frac{\rho \lambda^{\prime}}{\cos \left(\theta_{S Z}\right)}=\frac{\rho \lambda^{\prime}}{\sin \left(\theta_{S E}\right)}$

Dimana:

$P \lambda=$ reflektan TOA planetary

$\theta_{S E}=$ Sudut elevasi matahari lokal. Sudut elevasi matahari pada pusat citra dalam derajat diperoleh metadata (SUN_ELEVATION).

$\theta_{S Z}=$ Sudut zenit matahari lokal, $\theta_{S Z}=90^{\circ}-\theta_{S E}$

Sementara itu, nilai $P \lambda$ diperoleh dari persamaan berikut:

$\rho \lambda^{\prime}=M_{\rho} Q_{c a l}+A_{\rho}$

Dimana

$\rho \lambda^{\prime}=$ reflektan TOA planetary, tanpa koreksi sudut matahari.

$M_{\rho}=$ Band-spesifik perkalian faktor rescaling dari metadata

(REFLECTANCE_MULT_BAND_x, dimana $\mathrm{x}$ adalahnomor saluran)

$A_{\rho} \quad=$ Band-spesifik tambahan rescaling faktor dari metadata

(REFLECTANCE_ADD_BAND_x, dimana $\mathrm{x}$ adalah nomor saluran)

$Q_{c a l}=$ Nilai pixel standar produk terkuantisasi dan terkalibrasi (DN)

B. Koreksi Geomertrik

Koreksi geometrik merupakan suatu proses untuk menampilkan suatu citra sesuai dengan posisi sebenarnya di permukaan bumi melalui penyamaan koordinat-koordinat dipermukaan bumi. Koreksi koordinat ini penting karena citra-citra tersebut harus memiliki posisi yang sama untuk satu objek yang sama pada citra-citra yang berbeda sehingga bisa membandingkan nilai dari pixelpixel tersebut. Koreksi di lakukan di software ArcView dengan bantuan extension Image Analist.

C. Penghitungan Produktivitas Primer Kotor dan Serapan $\mathrm{CO}_{2}$ Vegetasi

Produktivitas primer kotor (PPK) merupakan total jumlah energi cahaya yang diubah menjadi energi kimia (senyawa organik) oleh autotrof suatu ekosistem selama suatu periode waktu
tertentu.Ada beberapa model yang digunakan untuk menghitung Produktivitas primer kotor dengan menggunakan data penginderaan jauh. Pada penelitian ini menggunakan model VPM (Xiao et al., 2004a; Xiao et al., 2004b; Xiao et al., 2005a; Xiao et al., 2005b). Adapun persamaan model VPM adalah:

$\mathrm{PPK}=\varepsilon_{\mathrm{g}} \times \mathrm{fPAR}_{\mathrm{chl}} \times \mathrm{PAR}$

Dimana PPK adalah produktivitas primer kotor $\left(\mathrm{gC} \mathrm{m}^{-2} \mathrm{waktu}^{-1}\right), \varepsilon_{\mathrm{g}}$ adalah Koefisien Efisiensi Penggunaan Cahaya $\left(\mathrm{gC} \mathrm{MJ}^{-1}\right)$, fPAR $\mathrm{PAV}$ adalah fraction of photosynthetically active radiation yang diserap oleh tanaman berklorofil, dan PAR adalah Photosynthetically Active Radiation $\left(\mathrm{MJ} \mathrm{m}^{-2} \mathrm{waktu}^{-1}\right)$.

\subsubsection{Perhitungan Emisi $\mathrm{CO}_{2}$}

Emisi $\mathrm{CO}_{2}$ dihitung dari semua sumber, yaitu sumber titik (point 
source), sumber area (area source), dan sumber bergerak menggunakan perhitungan standar Tier-3 Kementerian

Lingkungan Hidup(2013). Perhitungan emisi dilakukan dengan menggunakan rumus sbb:

$E_{t}=A D_{t} \times E F$

Keterangan:

$\mathrm{E}_{\mathrm{t}} \quad=$ Jumlah emisi pada tahun $\mathrm{t}$

$\mathrm{AD}_{\mathrm{t}} \quad=$ Data Aktivitas pada tahun $\mathrm{t}$

$\mathrm{EF} \quad=$ Faktor emisi

$\mathrm{t}=$ Periode tahun proyeksi

\section{HASIL DAN PEMBAHASAN}

\subsection{Serapan $\mathrm{CO}_{2}$}

Berdasarkan hasil analisis dengan menggunakan 8 lembar data Landsat 8 diperoleh bahwa nilai total GPP yang di Kota Denpasar berkisar antara 1.336,09 tC/8-hari sampai 1.572,89 tC/8-hari. Nilai tertinggi terdapat pada rentang tanggal 10-17 Mei 2016 dan terendah terdapat pada rentang tanggal 3-10 Februari 2015. Sementara itu bila di hitung per tahun, dengan mengasumsikan nilai GPP yang tidak memiliki data adalah sama seperti nilai GPP tanggal terdekat, maka diperoleh total GPP pada tahun 2015 di Kota Denpasar $\quad$ sebesar $\quad 64.297,96$
tC/tahun.Gambar 2 menunjukkan contoh sebaran GPP pada tanggal15 April 2015.

Hasil analisis GPP menunjukan jumlah C (karbon) yang terserap oleh tanaman saat proses fotosintesis. Hasil perhitungan dengan metode VPM tidak memperlihatkan jumlah $\mathrm{CO}_{2}$ (karbon dioksida) yang terserap oleh tanaman. Untuk menghitng jumlah $\mathrm{CO}_{2}$ yang terserap maka total GPP dikalikan dengan faktor konversi atom $\mathrm{C}$ di dalam senyawa $\mathrm{CO}_{2}$ yaitu sebesar 3,667 yang mengidikasikan perbandingan berat senyawa $\mathrm{CO}_{2}$ (44) dengan atom $\mathrm{C}$ (12). Berdasarkan nilai tersebut, maka diperoleh jumlah $\mathrm{CO}_{2}$ yang dapat terserap oleh tanaman di Kota Denpasar selama tahun 2015 adalah sebesar 235.780,63 $\mathrm{tCO}_{2} /$ tahun. 


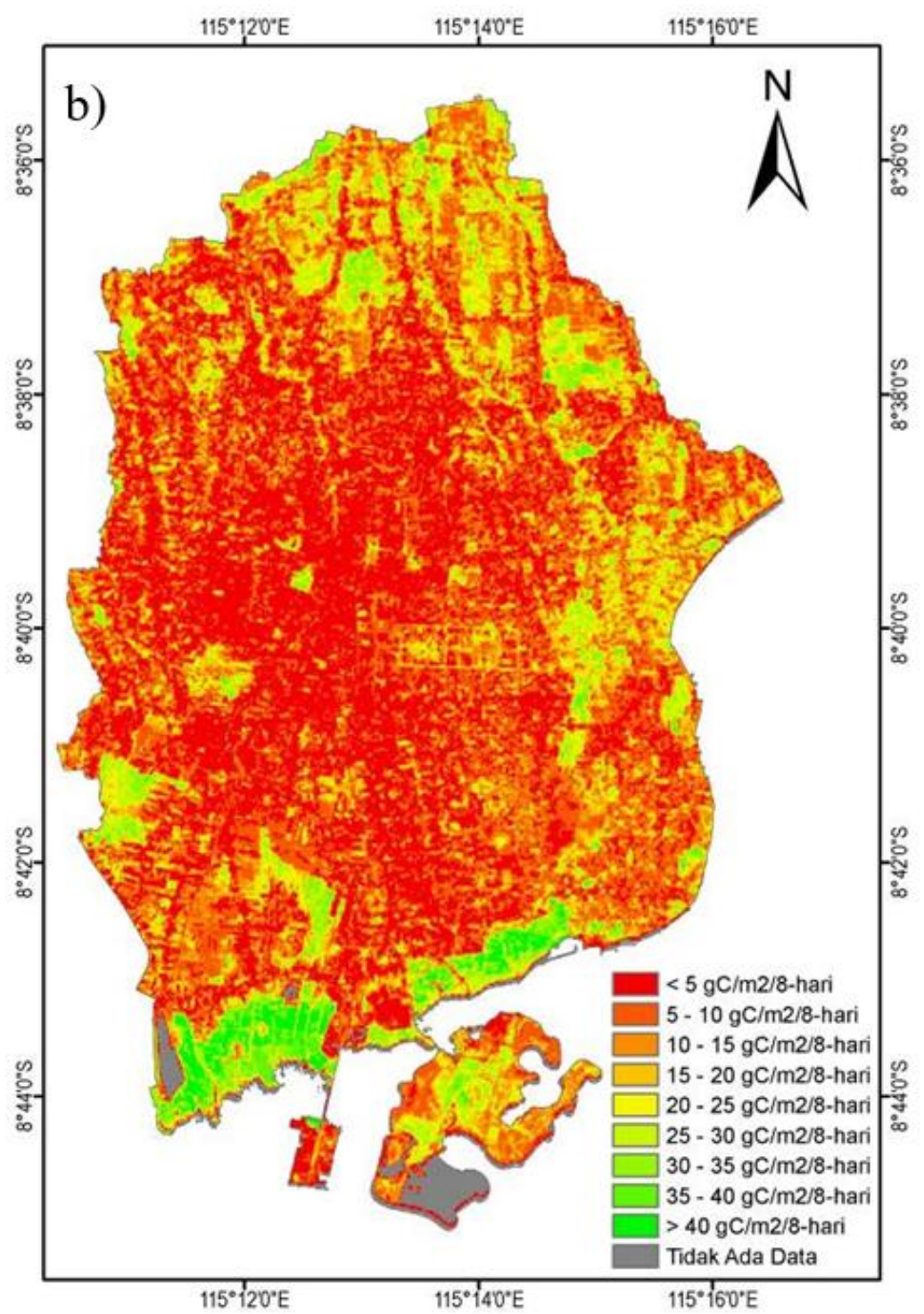

Gambar 2.

Pola spasial sebaran GPP di Kota Denpasar pada tanggal 15 April 2015

\subsection{Total Emisi $\mathrm{CO}_{2}$}

Berdasarkan perhitungan emisi $\mathrm{CO}_{2}$ dari sumber titik, area dan sumber bergerak dapat diketahui total emisi $\mathrm{CO}_{2}$ di Kota Denpasar adalah 862.955,86 ton/th. Penyumbang emisi $\mathrm{CO}_{2}$ terbesar adalah dari kendaraan bermotor, yaitu $862.822,90$ atau $99,985 \%$, kemudian diikuti oleh sumber area sebesar 95,31 ton/th $(0.011 \%)$, dan sumber titik berkontribusi terkecil, yaitu sebesar $37,65(0,004 \%)$ (Tabel1). Secara spasial, sebaran emisi $\mathrm{CO}_{2}$ di Kota Denpasar disajikan pada Gambar3.

Tabel1. Emisi $\mathrm{CO}_{2}$ bersumber dari sumber titik, area, dan sumber bergerak

\begin{tabular}{|l|r|r|}
\hline $\begin{array}{c}\text { SUMBER } \\
\text { EMISI }\end{array}$ & $\begin{array}{c}\mathbf{C O}_{2} \\
\text { (ton/th) }\end{array}$ & \multicolumn{1}{c|}{$\%$} \\
\hline Titik & 37,65 & 0,004 \\
\hline Area & 95,31 & 0,011 \\
\hline Bergerak & $862.822,90$ & 99,985 \\
\hline TOTAL & $862.955,86$ & 100 \\
\hline
\end{tabular}




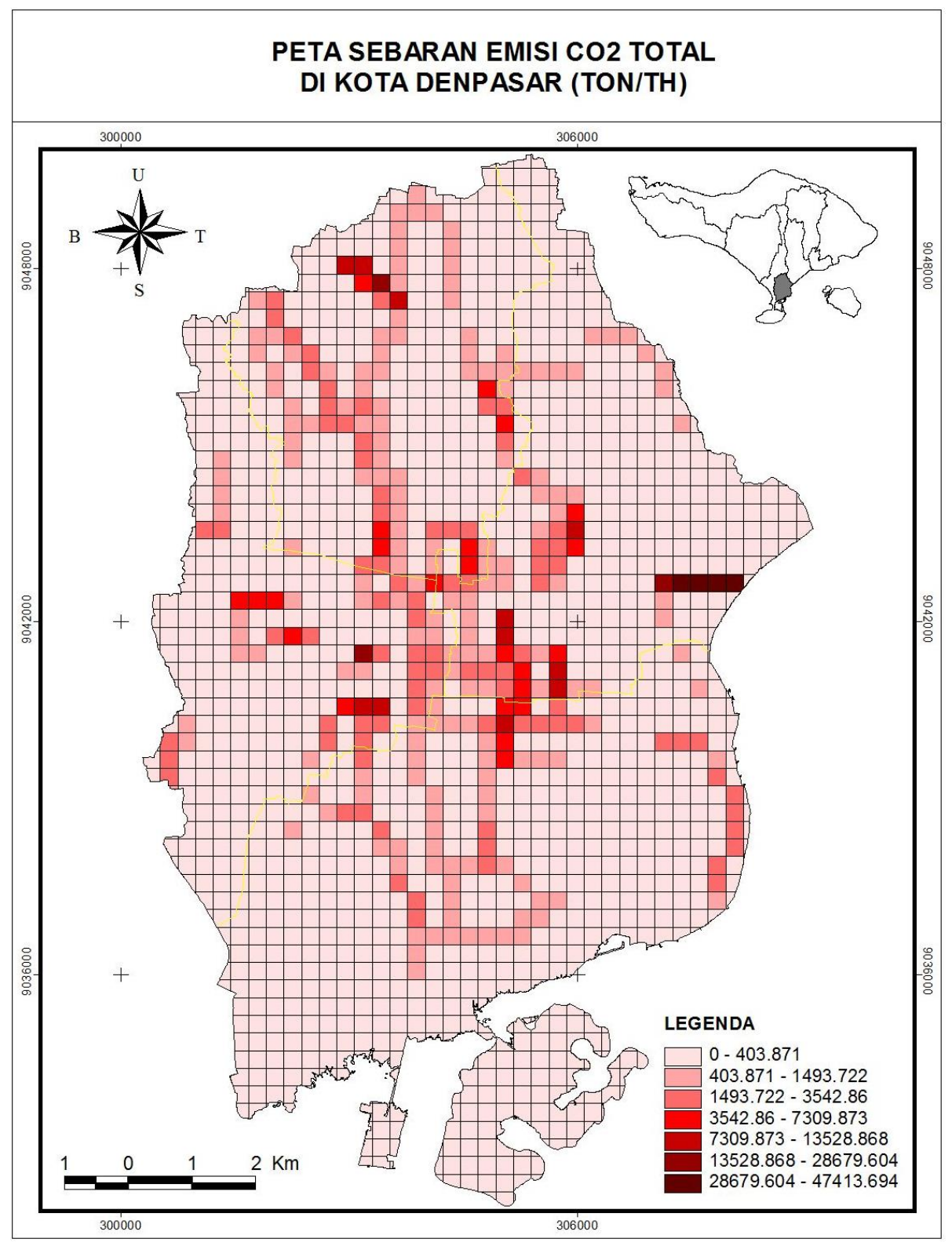

Gambar3.

Sebaran total emisi $\mathrm{CO}_{2}$ secaraspasial di Kota Denpasar

Bila dilihat lebih detail, pengumbang emisi $\mathrm{CO}_{2}$ terbesar dari sumber bergerak adalah kelompok kendaraan ringan sebesar 540.355,88 ton/tahun atau $62,63 \%$ dari seluruh emisi $\mathrm{CO}_{2}$ dari sumber bergerak. Kemudian diikuti oleh sepeda motor sebesar 260.187,43 ton/tahun atau $30,16 \%$. Kendaraan bis memberikan sumbangan pencemaran $\mathrm{CO}_{2}$ terkecil dari kendaraan bermotor, yaitu sebesar 9.589,79 ton/tahun atau

Tabel2. Kontribusi kendaraan bermotor terhadap emisi $\mathrm{CO}_{2}$

\begin{tabular}{|l|r|r|}
\hline $\begin{array}{l}\text { JENIS } \\
\text { KENDARAAN }\end{array}$ & \multicolumn{1}{c|}{$\begin{array}{c}\text { EMISI } \\
\text { (TON/TH) }\end{array}$} & \multicolumn{1}{c|}{$\%$} \\
\hline $\begin{array}{l}\text { Kendaraan } \\
\text { ringan }\end{array}$ & $540.355,88$ & 62,63 \\
\hline Bis & $9.589,79$ & 1,11 \\
\hline Sepeda motor & $260.187,43$ & 30,16 \\
\hline Kendaraan berat & $52.689,80$ & 6,11 \\
\hline TOTAL & $862.822,90$ & 100,00 \\
\hline
\end{tabular}


Berdasarkan data dari Badan Pusat Statistik Kota Denpasar tahun 2015, sepeda motor merupakan kendaraan bermotor yang mempunyai jumlah terbanyak, yaitu mencapai 1.038.345. Sementara itu, kendaraan ringan menempati jumlah terbanyak kedua, yaitu sebanyak 206.022. Termasuk di dalam kategori kendaraan ringan adalah sedan, jeep, minibus, dan pick up. Bis dan truk merupakan kendaraan dengan jumlah paling sedikit dengan jumlah masing-masing $\quad 12.395$ dan 3.462 (Tabel3).

\subsection{Perbandingan serapan dan Emisi $\mathrm{CO}_{2}$}

Total emisi $\mathrm{CO}_{2}$ per tahun di Kota Denpasar pada tahun 2015 adalah862.955,86 $\quad \mathrm{tCO}_{2} /$ tahun. Sementara itu kemampuan vegetasi yang berupa ruang terbuka hijau di Kota Denpasar hanya mampu menyerap $\mathrm{CO}_{2}$ sebesar 235.780,63 $\quad \mathrm{tCO}_{2} /$ tahun.Ini berarti jumlah emisi $\mathrm{CO}_{2}$ di Kota Denpasar 3,66 kali lebih besar dari kemampuan tanaman menyerap $\mathrm{CO}_{2}$. Hal ini yang menjadi penyebab kenapa suhu di Kota Denpasar semakin hari semakin meningkat. Hasil penelitian Nuarsa dkk (2012) dan As-syakur et al
(2012) menunjukkan bahwa terjadi peningkatan suhu di Kota Denpasar sebesar $2,16^{\circ} \mathrm{C}$ selama 8 tahun (19952003). Abda dkk. (2017) juga melakukan penelitian monitoring suhu di Kota Denpasar dari tahun 2003 sampai 2015 yang menyimpulkan bahwa pada kurun waktu tersebut terjadi peningkatan suhu di Kota Denpasar sebesar $1,7^{\circ} \mathrm{C}$, seiring dengan penurunan tutupan vegetasi sebesar $7,65 \%$.

Hasil simulasi terhadap estimasi tutupan vegetasi dan pertambahan penduduk di Kota Denpsar diperoleh bahwa serapan $\mathrm{CO}_{2}$ menurun dari tahun ketahun, sedangkan emisi $\mathrm{CO}_{2}$ meningkat secara signifikan. Gambar 4 menunjukkan terjadi gap yang semakin besar Antara serapan dan emisi $\mathrm{CO}_{2}$ di Kota Denpasar. Perpotongan emisi dan serapan $\mathrm{CO}_{2}$ terjadi pada tahun 1993, yang berarti jumlah serapan dan emisi $\mathrm{CO}_{2}$ pada tahun itu adalah sama. Sebelum tahun 1993 kemampuan vegetasi di Kota Denpasar untuk menyerap $\mathrm{CO}_{2}$ masih lebih besar dari total emisi, sementara setelah tahun 1993 jumlah emisi melebihi kemampuan vegetasi menyerap $\mathrm{CO}_{2}$, dan semakin tahun terjadi gap yang semakin tinggi (Gambar 4). 


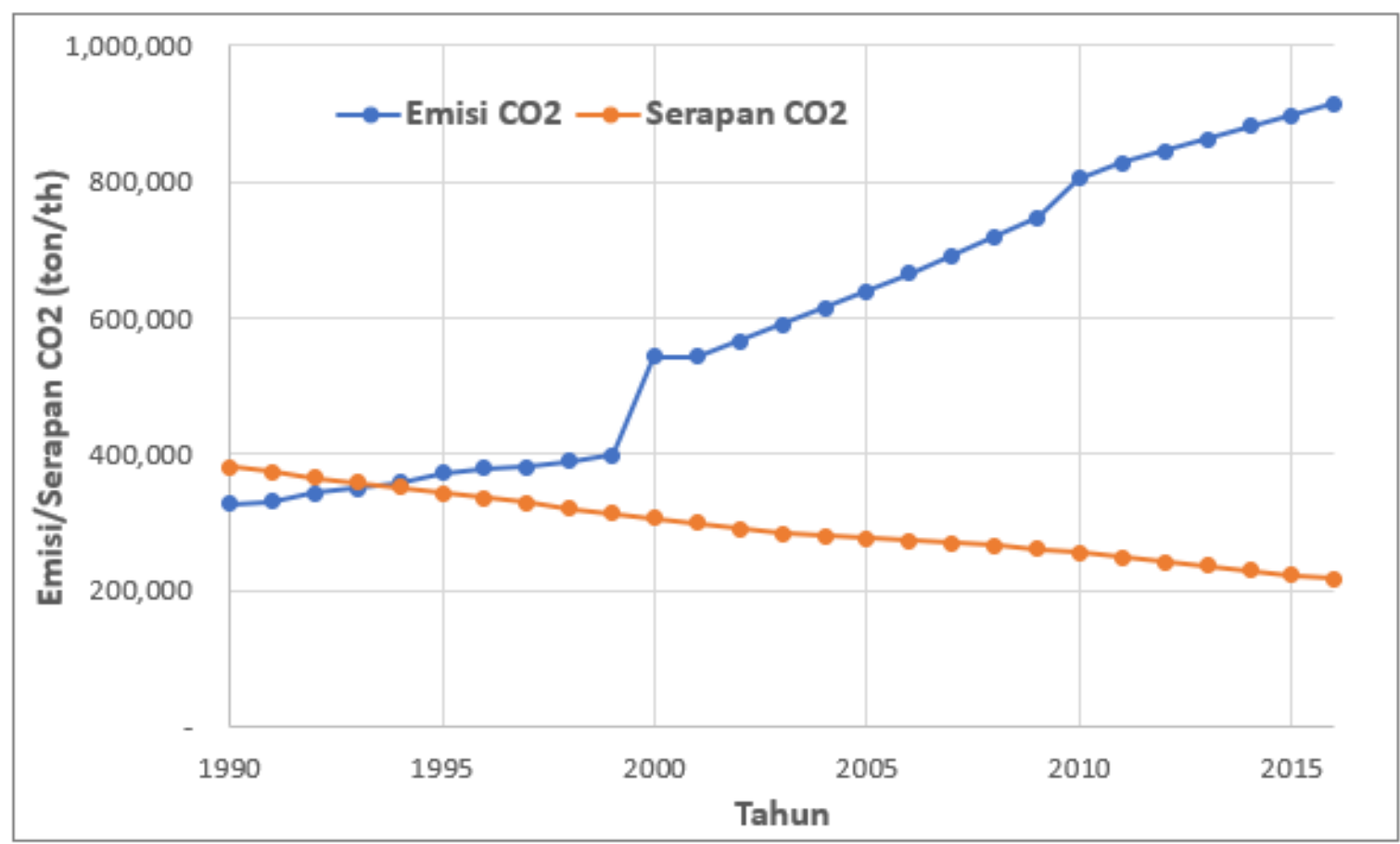

Gambar 4.

Hasil simulasi perbandingan serapan dan emisi $\mathrm{CO}_{2}$ di Kota Denpasar (1990-2015)

Beberapa rekomendasi yang dapat dilakukan untuk mengurangi emisi $\mathrm{CO}_{2}$ dan sekaligus meningkatkan serapan $\mathrm{CO}_{2}$ oleh vegetasi di Kota Denpasar adalah mengurangi jumlah kendaraan pribadi dengan memperbaiki system transportasi publik. Menambah dan memperbaiki kualitas ruang terbuka hijau yang ada saat ini dengan meningkatkan tingkat kerapatan dan memilih jenis tanaman yang mampu menyerap $\mathrm{CO}_{2}$ lebih banyak seperti Trembesi (Samaneasaman), Cassia (Cassia sp), Beringin (Ficusbenyamina), Mahoni (Swettianamahagoni) dan sebagainya merupakan cara lain yang juga penting untuk dilakukan. Konversi sumber energy kendaraan dari BBM ke listrik merupakan alternatif yang perlu dipertimbangkan. Sebagai contoh emisi $\mathrm{CO}_{2}$ dengan menggunakan energy konvensional adalah 70-80 $\mathrm{g} / \mathrm{km}$, sedangkan elektrik sebesar 0-5 g/km.

\section{SIMPULAN DAN SARAN}

\subsection{Simpulan}

1. Jumlah $\mathrm{CO}_{2}$ yang dapat diserap oleh vegetasi di Kota Denpasar pada tahun 2015 adalah 235.780,63 ton/tahun.

2. Total emisi gas $\mathrm{CO}_{2}$ di Kota Denpasar tahun 2015 adalah862.955,86 ton/tahun, diantaranya berasal dari sumber titik 37,65 ton/tahun $(0,004 \%)$, dari sumber area 95,31 ton/tahun $(0,011 \%)$, dan dari sumber bergerak sebesar 862.922,90 ton/tahun $(99,985 \%)$.

3. Dari sumber bergerak yang merupakan penyumbang emisi $\mathrm{CO}_{2}$ terbersar, kendaraan ringan adalah penyumbang emisi tertinggi, yaitu sebesar $540.355,88$ ton/tahun(62,63\%). Kemudian diikuti oleh sepeda motor sebesar 260.187,43 ton/tahun $(30,16 \%)$. Semntara itu kendaraan berat dan bis hanya 
memberikan kontribusi terhadap emisi $\quad \mathrm{CO}_{2} \quad$ masing-masing sebesar 52.689,80 ton/tahun $(6,11 \%)$ dan $9.589,79$ ton/tahun $(1,11 \%)$.

4. Jumlah emisi $\mathrm{CO}_{2}$ di Kota Denpasar 3,66 kali lebih besar dari kemampuan tanaman menyerap $\mathrm{CO}_{2}$ pada tahun 2015 dan ada tentensi gap ini akan semakin besar pada masa yang akan dating

\subsection{Saran}

Pembangunan transportasi public untuk mengurangi jumlah kendaraan pribadi harus segera dilakukan oleh pemerintah daerah. Peningkatan jumlah dan kualitas RTH perlu diperhatikan. Konversi sumber energy kendaraan dari BBM ke elektrik merupakan alternatif yang perlu dipertibangkan.

\section{DAFTAR PUSTAKA}

Abda'u, Mar'ie Zal, I Wayan Nuarsa, Ni Wayan Febriana Utami. 2017. AnalisisKorelasiPerubahanTutupan VegetasiTerhadapPerubahanSuhuU dara di Kota Denpasar. Ecotrophic, 11(2): $166-172$.

As-syakur Abd. R. , I W. Nuarsa, I W Arthana, M. S. Mahendra, I W. S. Adnyana, I N. Merit, R. Suyarto, and K. A. Lila. 2012. Remote Sensing Image-Based Analysis of the Urban Heat Island in Denpasar, Indonesia. 8th International Symposium on Lowland Technology, September 11-13, 2012 in Bali, Indonesia.

As-syakur, A.R., dan I W.S. Adnyana. 2009. "Analisis Indeks Vegetasi Menggunakan Citra Alos/Avnir-2 nan Sistem Informasi Geografi (SIG) Untuk Evaluasi Tata Ruang
Kota Denpasar". Jurnal Bumi Lestari, Vol.9, No. 1. 1-15.

BPS. 2015. Denpasar dalam Angka 2014. Badan Pusat Statistik. Denpasar

Diarniti, N.M. 2007. Monitoring of the Vegetation Coverage Using Vegetation Index in Denpasar during 1994 - 2003. Thesis. Master Program. Study Program of Environmental Science PostGraduate Program Udayana University. Denpasar.

Horning, N. 2004. Global Land Vegetation; An Electronic Textbook.

NASAGoddardSpaceFlightCenter Earth Sciences Directorate Scientific and Educational Endeavors (SEE). Versi on line. Dikunjungi pada tanggal 27 Desember 2007. http://www.ccpo.odu.edu/SEES/ve get/vg_class.htm

Ji, L., dan A.J. Peters. 2007. "Performance Evaluation of Spectral Vegetation Indices Using a Statistical Sensitivity Function". Remote Sensing of Environmental, $106,59-65$

Kementerian Lingkungan Hidup, 2013. Buku I : Pedoman Umum Penyelenggaraan Inventarisasi Gas Rumah Kaca Nasional.

Nowak, D.J., P.J. McHale, M. Ibarra, D. Crane, J.C. Stevans, dan C.J. Luley. 1998. Modeling the Effects of Urban Vegetation on Air Pollution. Air Pollution Modeling and Its Application, 12. 399-407 
Nuarsa, I Wayan 2013. Penggunaan Teknologi Penginderaan Jauh dan Sistem Informasi Geografis untuk Menghitung Persentase Ruang Terbuka Hijau di Daerah Permukiman Kota Denpasar. Jurnal Bumi Lestari, 13(1):9-15.

Nuarsa, I Wayan and Fumihiko Nishio. 2007. Relationships between Rice Growth Parameters and Remote Sensing Data. International Journal of Remote Sensing and Earth Sciences, (4):102-112

Nuarsa, I Wayan, Fumihiko Nishio, and Chiharu Hongo. 2010. Modification of Input Images for Improving the Accuracy of Rice Field Classification Using MODIS Data. International Journal of Remote Sensing and Earth Sciences, (7):36-52.

Nuarsa, I Wayan, Fumihiko Nishio, and Chiharu Hongo. 2011. Spectral Characteristics and Mapping of Rice Plants Using Multi-Temporal Landsat Data. Journal of Agricultural Science. 3(1): 54-67

Nuarsa, I Wayan, Fumihiko Nishio, Chiharu Hongo, and I Gede Mahardika. 2012. Using variance analysis of multitemporal MODIS images for rice field mapping in Bali Province, Indonesia. International Journal of Remote Sensing. 33(17):5402-5417

Nuarsa, I Wayan, I Nyoman Merit, I Wayan Sandi Adnyana, dan Abd. Rahman As-syakur. 2012. Studi Fenomena Urban Heat Island di Kota Denpasar dengan Menggunakan Data Penginderaan Jauh dan Sistem Informasi Geografi (SID). Laporan Grup
Riset, Lembaga Penelitian dan Pengabdian kepada Masyarakan (LPPM) Universitas Udayana

Nuarsa, I Wayan, Susumu Kanno, Yasuhiro Sugimori, and Fumihiko Nishio. 2005. Spectral Characterization of Rice Field Using Multi-Temporal Landsat ETM+ Data. International Journal of Remote Sensing and Earth Science, (2):65-71.

Purnomohadi, Ning. 2006. Ruang Terbuka Hijau Sebagai Unsur Utama Tata Ruang Kota, Direktorat JenderalPenataan Ruang Kementrian Pekerjaan Umum.

Tinambunan, R.S. 2006. Analisis Kebutuhan Ruang Terbuka Hijau Di Kota Pekanbaru (Tesis). Pengelolaan Sumber Daya Alam Dan Lingkungan Sekolah Pascasarjana Institut Pertanian Bogor. Bogor

UGGS, 2014. Landsat 8. United States Geological http://www.usgs.gov. Diakses

Xiao, X., Q. Zhang, S. Saleska, L. Hutyra, P. de Camargo, S. Wofsy, S. Frolking, S. Boles, M. Keller, and B. Moore. 2005a. SatelliteBased Modeling of Gross Primary Production in a Seasonally Moist TropicalEvergreenForest. Remote Sensing of Environment, 94, 105122

Xiao, X., Q.Y. Zhang, B. Braswell, S. Urbanski, S. Boles, S. Wofsy, B. Moore, and D. Ojima. 2004b. Modeling gross primary production of temperate deciduous broadleaf forest using satellite images and 
climate data. Remote Sensing of Environment, 91. 256-270.

Xiao, X., Q.Y. Zhang, D. Hollinger, J. Aber, and B. Moore. 2005b. Modeling gross primary production of an evergreen needleleaf forest using MODIS and climate data. Ecological Application, vol. 15, 954-969.
Xiao. X., D. Hollinger, J. Aber, M. Goltz, and Q. Zhang. 2004a. Satellite-based Modeling of Gross Primary Production in an EvergreenNeedleLeafForest. Remote Sensing of Environment, 89, 519-534. 